ఠ

\title{
Fixed combination of amlodipine and atorvastatin in cardiovascular risk management: patient perspectives
}

This article was published in the following Dove Press journal:

Vascular Health and Risk Management

5 May 2009

Number of times this article has been viewed

\author{
Madhuri Devabhaktuni' \\ Sripal Bangalore ${ }^{2}$ \\ 'Department of Medicine, Division \\ of Cardiology, St Luke's Roosevelt \\ Hospital, Columbia University College \\ of Physicians and Surgeons, New York, \\ NY, USA; 'Brigham and Women's \\ Hospital, Harvard Medical School, \\ Boston, MA, USA
}

\begin{abstract}
Hypertension and dyslipidemia are two of the most commonly co-occurring cardiovascular risk factors which together cause an increase in coronary heart disease-related events that is more than simply additive for anticipated event rates with each condition. Data have shown that even relatively small reductions in both blood pressure and cholesterol levels can lead to large reductions in the risk for cardiovascular events. However, though there are robust data on the beneficial effect of concomitant reduction in these risk factors, the reality is that this is achieved in $<10 \%$ of patients. There is nonadherence with prescribed therapies with up to $50 \%$ of patients stopping their medications of their own volition for a variety of reasons. There is a reasonable evidence base to suggest that simplifying drug regimens and reducing pill burden will enhance patient adherence. The fixed-dose combination containing the antihypertensive agent amlodipine besylate and the statin atorvastatin is the first combination of its kind, which is both efficacious and safe and could potentially improve medication compliance, thereby improving the outcomes in these patients.
\end{abstract}

Keywords: amlodipine, atorvastatin, compliance, dyslipidemia, fixed-dose combination, hypertension

\section{Introduction}

Coronary artery disease (CAD) is the leading cause of morbidity and mortality worldwide accounting for in excess of 930,000 deaths with an estimated direct and indirect cost of US $\$ 448.5$ billion in $2008 .{ }^{1}$ It is a multifactorial disease, emphasizing the need to treat an individuals' overall cardiovascular risk, rather than single risk factors in isolation. ${ }^{2}$

Hypertension and dyslipidemia are two of the most commonly co-occurring cardiovascular risk factors. In a recent study utilizing data from the third National Health and Nutrition Examination Survey (NHANES) it was estimated that almost 15\% of US adults (representing approximately 30 million persons) have both hypertension and dyslipidemia. ${ }^{3}$ It was also shown that more than $64 \%$ of patients with hypertension also have dyslipidemia; conversely, approximately $47 \%$ of patients with dyslipidemia have hypertension. ${ }^{3}$ These two risk factors together cause an increase in coronary heart disease-related events that is more than simply additive for anticipated event rates with each disease.

\section{Antihypertensive and lipid-lowering therapy and current practice}

Antihypertensive and lipid-lowering medications substantially reduce the risk of CAD, stroke, and death in patients with cardiovascular risk factors. ${ }^{4-6}$ Data have highlighted submit your manuscript $\mid$ www.dovepress.com

Dovepress 
the importance of prompt and 'aggressive' control of blood pressure (BP) and cholesterol for patients with hypertension alone and for patients with additional cardiovascular risk factors including dyslipidemia and diabetes. ${ }^{5,7,8}$ Recent trials indicate that patients with hypertension and concomitant multiple cardiovascular risk factors can benefit from lipidlowering therapy regardless of their baseline lipid levels. ${ }^{5}$

Although the importance of treating hypertension and dyslipidemia is well established in treatment guidelines, the current rate of control is unsatisfactory. In a managed care population of 154,235 patients, $>90 \%$ of patients in whom both hypertension and dyslipidemia had been diagnosed had not met treatment goals for both conditions. ${ }^{9}$ Suboptimal treatment patterns exist despite national and international guidelines. ${ }^{10,11}$ Moreover there is nonadherence with prescribed therapies; up to $50 \%$ of patients choose to stop their medications of their own volition for a variety of reasons. ${ }^{12}$ Factors reported to influence adherence include patient education and attitudes towards treatment, cost, complexities of treatment regimen, numbers of concomitant medications, and side effects. ${ }^{13,14}$

There is, therefore, a reasonable evidence to suggest that simplifying drug regimens and reducing pill burden may enhance patient adherence. ${ }^{13,14}$ A retrospective study of patient adherence to antihypertensive and lipid-lowering therapy demonstrated improvements in adherence if both therapies were initiated simultaneously, and if fewer other medications were taken concomitantly. ${ }^{13}$ The logic of combining multiple risk interventions for this multifactor disease is self evident and might be expected to enhance patient adherence and, therefore, improve achievement of treatment targets and reduce overall cardiovascular risk.

\section{Combination therapy in cardiovascular disease}

Polypharmacy and complex treatment regimens have been identified as important, modifiable risk factors for medication noncompliance. Poor compliance to medication regimen contributes to the practice-outcome gap, in which clinical guidelines are implemented but expected benefits are not realized. Fixed-dose combinations have the potential to improve compliance by reducing the pill burden (polypharmacy). A meta-analysis of nine studies which compared fixed-dose combinations versus free-drug components of the regimen, showed that fixed-dose combinations decreased the rate of nonadherence by $26 \%$ compared with free-drug component regimens (Figure 1). ${ }^{15}$ A subgroup analysis of the four

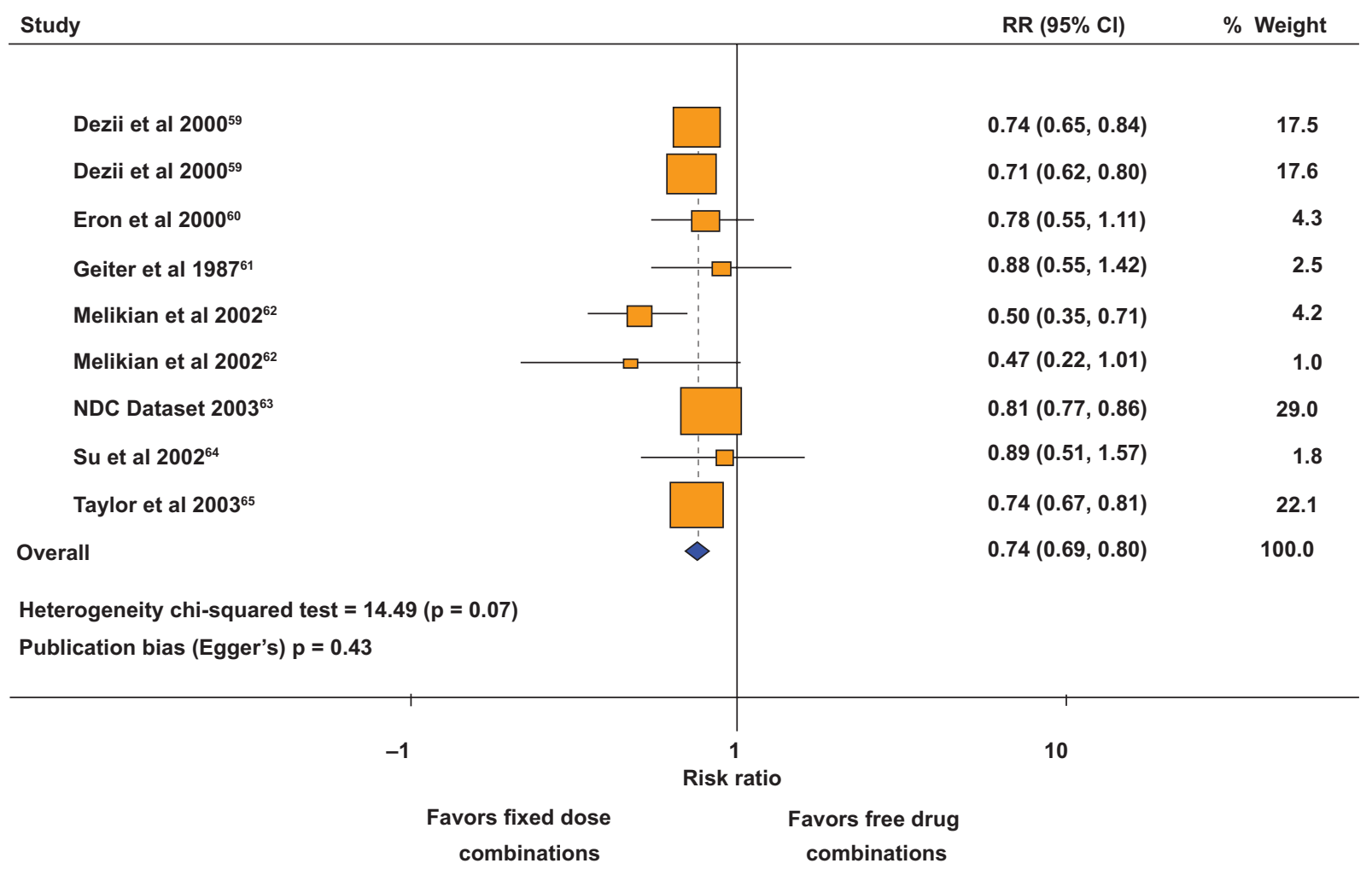

Figure I Effect of fixed-dose combinations versus free-drug combination on the risk of medication nonadherence. Copyright (C) 2007, Elsevier. Adapted from Bangalore S, Kamalakkannan G, Parkar S, et al. Fixed-dose combinations improve medication compliance: a meta-analysis. Am J Med. 2007;120:7I3-7I9. 
studies on hypertension showed that fixed-dose combination decreased the risk of medication noncompliance by $24 \%$ compared with free-drug combination regimens. ${ }^{15}$

The fixed-dose combination containing the antihypertensive agent amlodipine and the statin, atorvastatin, is the first combination of its kind designed to treat two risk factors for cardiovascular disease (CVD). This article provides an overview of this combination.

\section{Overview of pharmacology of atorvastatin and amlodipine Amlodipine component}

Amlodipine besylate, a 3rd generation dihydropyridine calcium channel blocker (CCB), is approved for the treatment of hypertension and both vasospastic and chronic stable angina, alone or in combination with other agents. The primary action of amlodipine is to inhibit calcium entry through voltage-gated transmembrane L-type channels, thus decreasing intracellular calcium concentration and inducing smooth muscle relaxation. ${ }^{16}$ Several important processes in atherosclerosis are influenced by calcium channel blockers, as they require calcium-dependent energy. Amlodipine also mediates nitric oxide release via a kinin-dependent mechanism ${ }^{17}$ and modulates the metabolism of collagens within the extracellular matrix, and thus potentially has anti-atherosclerotic-plaquestabilizing properties as well. ${ }^{18,19}$ It has further been proposed that amlodipine's apparent anti-atherosclerotic properties are related to its strong lipophilicity and membrane location, allowing it to modulate the atherosclerotic process via both calcium-dependent and calcium-independent pathways. ${ }^{19}$

\section{Atorvastatin component}

Atorvastatin calcium is a synthetic lipid-lowering agent and is an inhibitor of 3-hydroxy-3-methylglutaryl-coenzyme A (HMG-CoA) reductase, which catalyzes the conversion of HMG-CoA to mevalonate. Inhibition of HMG-CoA reductase leads to upregulation of low-density lipoprotein cholesterol (LDL-C) receptors in the liver, mediated by activation of sterol regulatory element-binding proteins resulting in enhanced clearance of LDL from the circulation and thus has an important role in preventing atherosclerosis. Atorvastatin, a second-generation statin, was introduced in 1996 and reduces LDL-C by $41 \%-61 \%$ in hypercholesterolemic patients.

\section{Pharmacokinetic properties}

\section{Amlodipine/atorvastatin}

The rate and extent of absorption of both amlodipine and atorvastatin after administration of a fixed-dose combination tablet has been shown to be similar to those after coadministration of matching doses of each single agent in healthy volunteers in a randomized, two-way crossover study. ${ }^{20}$ In elderly patients, the clearance of amlodipine is reduced compared with in younger recipients, causing an increase of approximately $40 \%-60 \%$ in the area under the plasma concentration-time curve (AUC). As a result, a lower initial dose of amlodipine may be required in this patient group. The pharmacokinetics of amlodipine is not significantly affected in patients with renal impairment. However, in patients with hepatic impairment, clearance is reduced to a similar extent as that demonstrated in elderly patients, and a lower initial dosage may be required. In patients with moderate to severe heart failure, the increase in amlodipine AUC was similar to that observed in elderly and patients with hepatic dysfunction. Atorvastatin is associated with higher plasma concentrations in the elderly (aged 65 years) than in younger patients, with a corresponding increase in lipid-lowering efficacy. Plasma concentrations of atorvastatin are markedly increased in patients with hepatic failure and the dosage may need to be reduced.

\section{Rationale for single-pill amlodipine/ atorvastatin therapy}

US epidemiological data have suggested that, on average, less than $10 \%$ of patients with concomitant hypertension and dyslipidemia are at target levels for both conditions. ${ }^{9,21}$ The large benefits that can result from simultaneous treatment of hypertension and dyslipidemia and the current suboptimal management of these conditions demonstrate that novel solutions are needed to treat the growing number of patients who have both of these important cardiovascular risk factors. Single-pill amlodipine/atorvastatin therapy represents such a solution.

The pharmacokinetic and pharmacodynamic properties of amlodipine and atorvastatin make them well suited for combination in a single pill to manage cardiovascular risk. ${ }^{22}$ The half-lives of both agents facilitate once-daily dosing, and both can be administered at any time of day with or without food. ${ }^{23}$ Neither drug has any adverse effects on the other's efficacy or tolerability. ${ }^{24-26}$

In addition a potential synergistic and dose-dependent increase in nitric oxide release was observed with combination treatment compared with individual components in a study on human vein endothelial cells taken from healthy volunteers. ${ }^{27}$ Moreover, combination therapy of amlodipine plus atorvastatin improved vascular compliance, an indicator of structural and functional vascular changes, and the 
beneficial effect on small arteries appeared to be more than additive. ${ }^{28,29}$ In normocholesterolemic obese hypertensive patients amlodipine plus atorvastatin reduced inflammatory markers and insulin resistance more than amlodipine therapy alone. ${ }^{30}$ Amlodipine has demonstrated some anti-atherosclerotic properties, whereas the beneficial effects of atorvastatin on atherosclerosis, via a reduction in cholesterol levels, are more marked. ${ }^{18}$

Hypertension is often associated with impaired fibrinolysis, usually expressed by increased levels of plasminogen activator inhibitor type 1 (PAI-1) and decreased activity of tissue plasminogen activator (t-PA) ${ }^{31}$ Combination therapy with amlodipine and atorvastatin improved the fibrinolytic balance more than either single agent in hypertensive hypercholesterolemic patients with insulin resistance. ${ }^{31}$

Study in transgenic ApoE * 3-Leiden mice demonstrates that amlodipine treatment alone did not significantly reduce atherosclerotic lesion development, whereas treatment with atorvastatin decreased lesion area substantially. The combination of amlodipine and atorvastatin tended to reduce atherosclerosis even more, possibly especially in modest statin responders, which may have implications for clinical practice. ${ }^{32}$ Mason and colleagues have observed that the combination of atorvastatin and amlodipine produces a synergistic reduction in oxidative damage to human LDL, an effect not observed with other combinations of amlodipine and statins. ${ }^{33}$

The Regression Growth Evaluation Statin Study (REGRESS) trial was designed to determine the effect of lipid-lowering therapy with pravastatin in symptomatic patients with normal to moderately raised cholesterol levels. Although the REGRESS trial was not designed to evaluate combination therapy, the results suggest strongly that addition of CCBs to statin acts synergistically in retarding the progression of established coronary atherosclerosis. ${ }^{34}$

\section{Key outcome trials}

\section{Amlodipine}

Amlodipine effectively lowers blood pressure and reduces the risk of cardiovascular morbidity and mortality. The major outcome trials of amlodipine are listed in Table 1.

\section{Hypertension trials}

The Irbesartan Diabetic Nephropathy Trial (IDNT) ${ }^{35}$ evaluated the effects of amlodipine or irbesartan or placebo in hypertensive patients with diabetic nephropathy. Although irbesartan was superior to amlodipine and placebo for the primary composite end point (doubling of the baseline serum creatinine concentration, the development of end-stage renal disease, or death from any cause), amlodipine reduced the time to a secondary, cardiovascular composite end point as effectively as irbesartan. ${ }^{35}$

In the Antihypertensive and Lipid-Lowering Treatment to Prevent Heart Attack Trial (ALLHAT), ${ }^{36}$ more than 40,000 high risk hypertensive patients were randomly assigned to receive chlorthalidone, amlodipine, lisinopril, or doxazosin. Amlodipine was as effective as chlorthalidone in reducing the primary combined endpoint of fatal coronary heart disease or nonfatal myocardial infarction. Moreover, it was more effective than lisinopril in reducing the risk of stroke. However, incidence of heart failure was 38\% higher in patients assigned to amlodipine than patients assigned to chlorthalidone.

Valsartan Antihypertensive Long-term Use Evaluation (VALUE) trial was designed to test the hypothesis that, for the same BP control, valsartan would reduce cardiac morbidity and mortality more than amlodipine in hypertensive patients at high cardiovascular risk. ${ }^{8}$ Amlodipine treatment was associated with a more prompt and robust reduction in BP than valsartan treatment, particularly early in the trial. The primary composite end point of cardiac mortality and morbidity was reduced equally by both groups. ${ }^{8}$ However, amlodipine was associated with a statistically significant $16 \%$ reduction in the incidence of myocardial infarction and a near-significant reduction in stroke (Table 1). Subanalysis of VALUE results reported that valsartan monotherapy reduced the risk of heart failure and new onset diabetes to a greater extent compared to amlodipine monotherapy. ${ }^{37}$ These data are consistent with the findings in ALLHAT that amlodipine does not prevent heart failure as effectively as some other antihypertensive drugs.

Anglo-Scandinavian Cardiac Outcomes Trial - Blood Pressure Lowering Arm (ASCOT-BPLA) ${ }^{38}$ compared a "standard" antihypertensive regimen ( $\beta$-blocker [atenolol] plus/ minus diuretic [thiazide]) with a more "contemporary" regimen (CCB [amlodipine] plus/minus ACE inhibitor [perindopril]) on the combined primary outcome (nonfatal myocardial infarction and fatal coronary heart disease). ${ }^{39}$ ASCOT-BPLA was terminated early due to benefits in cardiovascular mortality and all-cause mortality in patients treated with amlodipine versus atenolol-based treatment. Results from the ASCOT Conduit Artery Function Evaluation (CAFE) ${ }^{40}$ study assessed the effects of atenolol- versus amlodipine-based therapy on central arterial blood pressure and showed that central arterial blood pressure was more favorably influenced by the amlodipine- than the atenolol-based regimen when compared with 


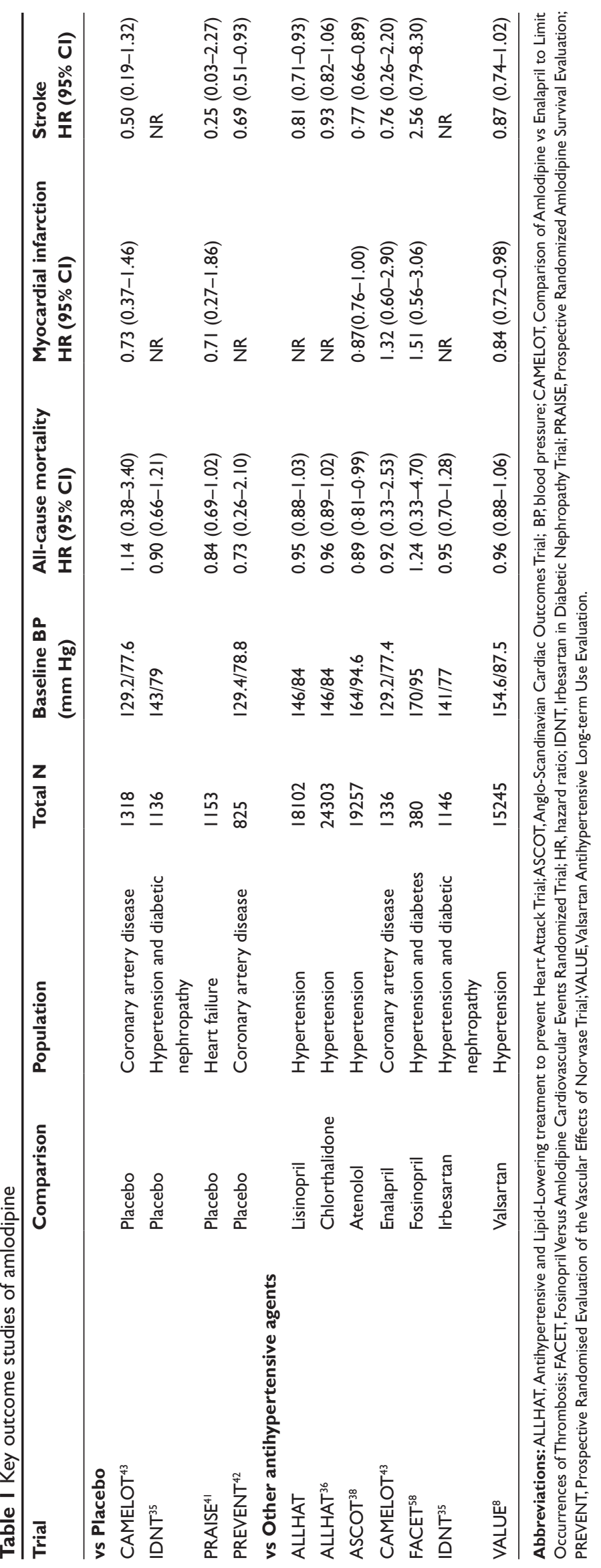


peripheral BP. Central, arterial pulse pressure was observed to be a more important and an independent predictor of cardiovascular and renal outcomes.

\section{Heart failure trials}

The Prospective Randomized Amlodipine Survival Evaluation Study (PRAISE) trial ${ }^{41}$ evaluated the safety of amlodipine in patients with severe heart failure with an ejection fraction $<30 \%$. Among patients with ischemic heart disease, there was no difference between the amlodipine and placebo groups in the occurrence of either death from any cause and hospitalization for major cardiovascular events. However, among patients with nonischemic cardiomyopathy, amlodipine reduced the combined risk of fatal and nonfatal events by $31 \%$ and decreased the risk of death by $46 \%$ and showed that it did not increase cardiovascular morbidity or mortality in patients with severe heart failure. ${ }^{41}$

\section{Coronary artery disease trials}

The other area of major randomized controlled trials of amlodipine have been in the cohort of patients with atherosclerosis. The Prospective Randomized Evaluation of the Vascular Effects of Norvasc Trial (PREVENT) was a multicenter, randomized, placebo-controlled, clinical trial designed to test whether amlodipine would slow the progression of early coronary atherosclerosis in patients with angiographically documented coronary artery disease. ${ }^{42}$ Although there was no difference in the coronary angiographic endpoint, there was a significant reduction in the progression of carotid atherosclerosis as well as a significant reduction in the risk of stroke.

Comparison of Amlodipine vs Enalapril to Limit Occurrences of Thrombosis (CAMELOT) ${ }^{43}$ study compared the incidence of cardiovascular events among patients with angiographically documented coronary artery disease and normal BP randomized to amlodipine, enalapril, or placebo. ${ }^{43}$ After 24 months, there was a significant reduction in the incidence of cardiovascular events in the amlodipine arm compared with placebo. Compared with baseline, intravascular ultrasound (IVUS) showed progression in the placebo group, a trend toward progression in the enalapril group $(p=0.08)$, but no progression in the amlodipine group $(\mathrm{p}=0.31)$.

\section{Atorvastatin}

Atorvastatin, like other statins, has been shown to reduce LDL cholesterol and reduce the risk of cardiovascular morbidity and mortality (Table 2). In addition, statins have pleiotropic effects.

\section{Coronary artery disease trials}

The Pravastatin or Atorvastatin Evaluation and Infection Therapy - Thrombolysis in Myocardial Infarction (PROVE IT-TIMI 22) trial compared standard treatment (pravastatin $40 \mathrm{mg}$ daily) with more intensive treatment (atorvastatin $80 \mathrm{mg}$ daily) in patients who had been hospitalized for an acute coronary syndrome within the preceding 10 days. ${ }^{44}$ The primary outcome was a composite of death from any cause, myocardial infarction, severe unstable angina, revascularization or stroke. A $16 \%$ reduction in the hazard ratio favored atorvastatin. The findings from PROVE IT-TIMI 22 have been confirmed by the results from the Treating to New Targets (TNT) Study. ${ }^{45}$

The TNT study examined the effectiveness of low-dose versus high-dose atorvastatin therapy on major cardiovascular events. TNT demonstrated that the use of atorvastatin $80 \mathrm{mg}$ to reduce LDL-C to $77 \mathrm{mg} / \mathrm{dL}$ provided additional clinical benefits in stable coronary heart disease patients, compared with reduction of LDL-C to $100 \mathrm{mg} / \mathrm{dL}$ with atorvastatin $10 \mathrm{mg}$. The composite primary outcome - first occurrence of a major cardiovascular event - showed a relative risk reduction of $22 \% .{ }^{46}$ TNT's findings confirm the growing body of evidence that reducing LDL-C below current guideline-recommended levels confers significant clinical benefits.

The Incremental Decrease in Endpoints through Aggressive Lipid Lowering (IDEAL) study compared patients with a history of acute myocardial infarction treated with a high dose of atorvastatin $(80 \mathrm{mg} /$ day) with those receiving the standard dose of simvastatin $(20 \mathrm{mg} /$ day $){ }^{47}$ Mean LDL-C levels were $104 \mathrm{mg} / \mathrm{dL}$ in the simvastatin group and $81 \mathrm{mg} / \mathrm{dL}$ in the atorvastatin group during treatment. The risk reduction between the treatment groups (11\%) in the primary endpoint of major coronary events failed to reach significance $(p=0.07)$. However, significant reductions favoring the atorvastatin treatment group were observed for the occurrence of secondary cardiovascular endpoints such as coronary events and nonfatal acute myocardial infarction.

The Reversal of Atherosclerosis with Aggressive Lipid Lowering (REVERSAL) study used the same doses of atorvastatin and pravastatin as the PROVE IT study in patients with angiographically demonstrated CAD. The results of the REVERSAL study showed that atorvastatin $80 \mathrm{mg}$ halted plaque progression (as monitored by IVUS), while pravastatin did not. ${ }^{48}$

The Aggressive Lipid-Lowering Initiation Abates New Cardiac Events (ALLIANCE) trial compared a focused treatment strategy using atorvastatin with usual medical care. 
Table 2 Key outcome studies of atorvastatin

\begin{tabular}{|c|c|c|c|c|c|c|}
\hline Trial & Study groups & Population & Total N & All-cause mortality & Myocardial infarction & Stroke \\
\hline ALLIANCE $^{49}$ & $\begin{array}{l}\text { Atorvastatin } \\
(10-80 \mathrm{mg}) \text { vs } \\
\text { Ongoing usual care }\end{array}$ & $\begin{array}{l}\text { Coronary artery } \\
\text { disease }\end{array}$ & 2442 & $0.92(0.72-1.18)$ & $0.52(0.38-0.74)$ & $0.87(0.55-1.38)$ \\
\hline ASCOT-LLA ${ }^{5}$ & $\begin{array}{l}\text { Atorvastatin (10 mg) } \\
\text { vs Placebo }\end{array}$ & $\begin{array}{l}\text { Substudy of patients } \\
\text { with hypertension, } \\
\text { average or lower } \\
\text { cholesterol, and at least } \\
\text { three other risk factors }\end{array}$ & 10305 & $0.87(0.7 \mathrm{I}-1.06)$ & $0.65(0.50-0.83)$ & $0.73(0.56-0.96)$ \\
\hline CARDS $^{7}$ & $\begin{array}{l}\text { Atorvastatin }(10 \mathrm{mg}) \\
\text { vs Placebo }\end{array}$ & $\begin{array}{l}\text { Patients with diabetes } \\
\text { without high LDL-C } \\
\text { levels }\end{array}$ & 2838 & $0.73(0.53-1.01)$ & $0.53(0.35-0.8 I)$ & $0.53(0.3 \mathrm{I}-0.90)$ \\
\hline GREACE $^{50}$ & $\begin{array}{l}\text { Atorvastatin } \\
(10-80 \mathrm{mg}) \text { vs usual } \\
\text { care by GP }\end{array}$ & Heart failure & 1600 & $0.58(0.35-0.95)$ & $0.46(0.32-0.66)$ & $0.53(0.24-0.18)$ \\
\hline PROVE IT ${ }^{44}$ & $\begin{array}{l}\text { Pravastatin }(40 \mathrm{mg}) \\
\text { vs atorvastatin } \\
(80 \mathrm{mg})\end{array}$ & $\begin{array}{l}\text { Acute coronary } \\
\text { syndromes }\end{array}$ & 4162 & $0.72(0.5-1.02)$ & $0.87(0.7-I .1)$ & I.08 (0.4-I.6) \\
\hline $\mathrm{TNT}^{46}$ & $\begin{array}{l}\text { Atorvastatin }(10 \mathrm{mg}) \\
\text { vs atorvastatin } \\
(80 \mathrm{mg})\end{array}$ & $\begin{array}{l}\text { Coronary artery } \\
\text { disease }\end{array}$ & 10001 & $1.01(0.85-1.19)$ & $0.78(0.69-0.89)$ & $0.75(0.59-0.96)$ \\
\hline IDEAL ${ }^{47}$ & $\begin{array}{l}\text { Atorvastatin }(80 \mathrm{mg}) \\
\text { vs simvastatin } 20 \mathrm{mg}\end{array}$ & $\begin{array}{l}\text { Coronary artery } \\
\text { disease }\end{array}$ & 8888 & $0.98(0.85-1.13)$ & $0.89(0.78-1.01)$ & $0.87(0.7-1.08)$ \\
\hline
\end{tabular}

Abbreviations: ALLIANCE, Aggressive Lipid-Lowering Initiation Abates New Cardiac Events; ASCOT-LLA, Anglo-Scandinavian Cardiac Outcomes Trial-Lipid Lowering Arm; CARDS, Collaborative Atorvastatin Diabetes Study; GREACE, Greek Atorvastatin and Coronary Heart Disease Evaluation; IDEAL, Incremental Decrease in Clinical Endpoints Through Aggressive Lipid Lowering; PROVE IT, Pravastatin or Atorvastatin Evaluation and Infection Therapy trial;TNT, Treating to New Targets.

The study showed that aggressive treatment with atorvastatin was associated with significantly lower LDL cholesterol levels over usual care accompanied by improved outcomes in the composite primary end point of cardiovascular events and particularly nonfatal myocardial infarction. ${ }^{49}$

The Greek Atorvastatin and Coronary-heart-disease Evaluation (GREACE) study assessed the effect of atorvastatin on mortality and morbidity in patients with coronary heart disease. The treatment regimen was atorvastatin, $10-80 \mathrm{mg} / \mathrm{day}$, titrated to LDL-C $<100 \mathrm{mg} / \mathrm{dL}$, or usual care. Total mortality was lower with atorvastatin than with usual care. Similar reductions with atorvastatin compared to usual care were seen in coronary mortality and coronary morbidity. ${ }^{50}$

\section{Hypertension and diabetes trials}

In the recent Collaborative Atorvastatin Diabetes Study (CARDS), atorvastatin $10 \mathrm{mg}$ reduced the death rate among patients with type 2 diabetes mellitus and relatively low-cholesterol levels by $27 \%$ compared with placebo. ${ }^{7}$ The CARDS study was terminated after approximately two years early due to the highly significant reduction in cardiovascular events, including heart attack and stroke, in those patients receiving atorvastatin treatment.
The lipid-lowering arm of the ASCOT trial investigated, in a factorial design, the effects of simultaneous treatment with antihypertensive and lipid-lowering therapy (atorvastatin $10 \mathrm{mg}$ ) among hypertensive patients with normal to mildly elevated lipid levels and at least three other cardiovascular risk factors. ${ }^{5}$ The lipid-lowering study arm was terminated nearly two years early due to the highly significant (36\%) decrease in the cumulative incidence of nonfatal myocardial infarction and CHD mortality among patients receiving treatment to lower both BP and lipids compared with patients receiving treatment for hypertension alone.

\section{Key studies evaluating amlodipine and atorvastatin combination therapy}

Clinical trials have been conducted (comparative and non comparative) to assess the efficacy and safety of the combination therapy. Single-pill therapy in the Treatment of Concomitant Hypertension and Dyslipidemia (GEMINI), ${ }^{22}$ GEMINI- Asia Pacific, Middle East, Africa, Latin America (GEMINI-ALAA), ${ }^{51}$ An international, multicenter, open label study to assess the effectiveness of amlodipine-atorvastatin 
combination in subjects with hypertension and dyslipidemia in the UK and Canada (JEWEL I), JEWEL Europe (JEWEL II), ${ }^{52}$ Clinical Utility of Caduet in Simultaneously Achieving Blood Pressure and Lipid End Points (CAPABLE) ${ }^{53}$ are noncomparative, titration-to-goal, multicenter studies, which showed the efficacy and effectiveness of the combination medication at achieving both LDL and BP goals. AVALON and RESPOND are two randomized double-blind, multicenter trials that compared the efficacy of the coadministration of amlodipine and atorvastatin with that of single-agent therapy or placebo over eight weeks. ${ }^{25,54}$ The Anglo-Scandinavian Cardiac Outcomes Trial-Lipid Lowering Arm (ASCOT-LLA) is a randomized, double-blind, multicenter trial that compared the efficacy of amlodipine plus atorvastatin with that of placebo over 3.3 years..$^{55}$

ASCOT-LLA study evaluated data from patients who had received atorvastatin $10 \mathrm{mg}$ once daily or placebo in addition to their antihypertensive regimen as described previously. ${ }^{55}$ In ASCOT-LLA, the relative risk of nonfatal myocardial infarction and fatal coronary heart disease was reduced by $36 \%$ in the group receiving atorvastatin plus either antihypertensive regimen compared with the group receiving placebo plus either antihypertensive regimen. ${ }^{5}$

In the multicenter Atorvastatin and Amlodipine in Patients with Elevated Lipids and Hypertension (AVALON) ${ }^{25}$ trial more patients receiving combination therapy achieved their BP goal than patients receiving atorvastatin, and more patients receiving combination therapy achieved their LDL-C goal than patients receiving amlodipine. ${ }^{25}$ Similarly, significantly more patients receiving combination therapy achieved both their BP and LDL-C goals compared with those receiving single-agent therapy. ${ }^{25}$ The mean Framingham estimated 10 -year CHD risk was significantly with combination therapy than with single-agent therapy.

In the Efficacy and Safety of Fixed-Dose Combinations of Amlodipine and Atorvastatin in the Treatment of Patients with Concomitant Hypertension and Dyslipidemia (RESPOND) $)^{54}$ study, hypertensive patients with dyslipidemia the concomitant use of amlodipine plus atorvastatin did not modify the efficacy achieved with either agent alone. ${ }^{54}$ In an analysis of risk, the mean Framingham estimated 10 -year CHD risk was reduced from mean baseline values of $15.8 \%-18.0 \%$ to endpoint values of $7.3 \%-10.7 \%$ in patients receiving combination therapy. ${ }^{54}$

\section{Tolerability/safety data}

In the double-blind phase of the AVALON trial, the rate of treatment discontinuation for any reason was similar in 
groups receiving amlodipine $5 \mathrm{mg}$ plus atorvastatin $10 \mathrm{mg}$ (7.7\%), amlodipine $5 \mathrm{mg}$ alone $(7.0 \%)$, or atorvastatin $10 \mathrm{mg}$ alone (7.5\%), but slightly higher in the placebo group (9.6\%). Adverse events reported most frequently in the combination therapy group compared with the placebo group during this phase were peripheral edema (5.3\% vs $2.1 \%$ ), myalgia (4.8\% vs $2.1 \%$ ), and sinusitis $(2.9 \%$ vs $0.8 \%) .{ }^{25}$ In RESPOND trial combination-treated patients did not experience any increase in treatment-related side effects compared with amlodipine or atorvastatin monotherapy. The most common treatment-related side effects were peripheral edema (9.4\% vs $2.7 \%$ ), headache and dizziness compared to placebo. These events were mild to moderate in severity. The incidence of treatment-related myalgia in combinationtreated patients was low $(1.0 \%)$ and similar to that in patients treated with amlodipine alone $(1.4 \%)$, atorvastatin alone $(1.1 \%)$, or placebo $(1.8 \%) .{ }^{54}$ GEMINI study showed that amlodipine/atorvastatin combination pill has a safety profile consistent with its components. These data demonstrated that co-administered amlodipine plus atorvastatin is well tolerated in patients with hypertension and additional risk factors, and that the adverse events observed are similar in nature, severity and frequency to those seen with amlodipine or atorvastatin administered alone.

\section{Pharmacoeconomic considerations/ quality of life}

Treatment with a single tablet of amlodipine/atorvastatin has been shown to be more cost effective than two-tablet therapy and may be slightly more effective when real world adherence levels are considered. ${ }^{56,57}$ It has been shown that the clinical and economic consequences of adding atorvastatin to an existing amlodipine-based antihypertensive regimen using a single-pill formulation versus a two-pill regimen among patients similar to the ASCOT-LLA population showed the single-pill formulation to be less costly and could be slightly more effective when real world adherence levels are considered. ${ }^{57}$

\section{Conclusion}

Concomitant hypertension and dyslipidemia are very common and are associated with a high risk of cardiovascular disease. Despite the widespread availability of safe and efficacious medications for the treatment of hypertension and dyslipidemia, the management of these conditions is far from optimal. Indeed, epidemiological studies have indicated that $90 \%$ of patients with concomitant hypertension and dyslipidemia fail to achieve their therapeutic targets for both conditions. Moreover, the optimal LDL goal in patients with risk factors has been steadily declining, necessitating the treatment of bigger population subsets.

Amlodipine and atorvastatin both have excellent efficacy and safety profiles for the treatment of hypertension and dyslipidemia, respectively. Clinical trials have shown that co-administration of these two agents, across the dose range, does not modify the efficacy of either medication. Moreover, the efficacy and safety of single-pill amlodipine/atorvastatin therapy has also been demonstrated in patients at different levels of risk for CVD. The association of amlodipine and atorvastatin in a single pill formulation with flexible dosing combinations offers the possibility of simplifying the process for treating hypertension and/or angina and dyslipidemia and thereby improving medication adherence. ${ }^{66}$ The concept of dual-therapy pill also highlights the importance of managing both the risk factors simultaneously, both for the practitioner and the patient and open the floodgates to development and release of other crossrisk-factor, single-pill combinations, and a future polypill.

\section{Disclosure}

The authors report no conflicts of interest in this work.

\section{References}

1. Rosamond W, Flegal K, Furie K, et al. Heart disease and stroke statistics - 2008 update: a report from the American Heart Association Statistics Committee and Stroke Statistics Subcommittee. Circulation. 2008;117(4):e25-e146.

2. Volpe M, Alderman MH, Furberg CD, et al. Beyond hypertension toward guidelines for cardiovascular risk reduction. Am J Hypertens. 2004 Nov; 17(11 Pt 1):1068-1074.

3. National Center for Health Statistics. Feb 24, 2008. Accessed on Jan 10, 2009. Available from: http://www.cdc.gov/nchs/.

4. Heart Protection Study Collaborative Group. MRC/BHF Heart Protection Study of cholesterol lowering with simvastatin in 20,536 high-risk individuals: a randomised placebo-controlled trial. Lancet. 2002;360(9326):7-22

5. Sever PS, Dahlof B, Poulter NR, et al. Prevention of coronary and stroke events with atorvastatin in hypertensive patients who have average or lower-than-average cholesterol concentrations, in the Anglo-Scandinavian Cardiac Outcomes Trial-Lipid Lowering Arm (ASCOT-LLA): a multicentre randomised controlled trial. Lancet. 2003;361(9364): 1149-1158.

6. Turnbull F. Effects of different blood-pressure-lowering regimens on major cardiovascular events: results of prospectively-designed overviews of randomised trials. Lancet. 2003;362(9395):1527-1535.

7. Colhoun HM, Betteridge DJ, Durrington PN, et al. Primary prevention of cardiovascular disease with atorvastatin in type 2 diabetes in the Collaborative Atorvastatin Diabetes Study (CARDS): multicentre randomised placebo-controlled trial. Lancet. 2004;364(9435):685-696.

8. Julius S, Kjeldsen SE, Weber M, et al. Outcomes in hypertensive patients at high cardiovascular risk treated with regimens based on valsartan or amlodipine: the VALUE randomised trial. Lancet 2004;363(9426):2022-2031.

9. Pettitt D, Karter AJ, Peng TY, et al. The impact of concurrent dyslipidemia and diabetes on hypertension management and goal attainment. Vancouver, Canada: Poster presentation at the 26th Annual Meeting of the Society of General Internal Medicine; 2003. 
10. EUROASPIRE I and II Group; European Action on Secondary Prevention by Intervention to Reduce Events.Clinical reality of coronary prevention guidelines: a comparison of EUROASPIRE I and II in nine countries. EUROASPIRE I and II Group. European Action on Secondary Prevention by Intervention to Reduce Events. Lancet. 2001;357(9261):995-1001.

11. Pearson TA, Laurora I, Chu H, Kafonek S. The lipid treatment assessment project (L-TAP): a multicenter survey to evaluate the percentages of dyslipidemic patients receiving lipid-lowering therapy and achieving low-density lipoprotein cholesterol goals. Arch Intern Med. 2000;160(4):459-467.

12. Insull $\mathrm{W}$. The problem of compliance to cholesterol altering therapy. J Intern Med. 1997;241(4):317-325.

13. Chapman RH, Benner JS, Petrilla AA, et al. Predictors of adherence with antihypertensive and lipid-lowering therapy. Arch Intern Med. 2005;165(10):1147-1152.

14. Schroeder K, Fahey T, Ebrahim S. How can we improve adherence to blood pressure-lowering medication in ambulatory care? Systematic review of randomized controlled trials. Arch Intern Med. 2004;164(7):722-732.

15. Bangalore S, Kamalakkannan G, Parkar S, Messerli FH. Fixed-dose combinations improve medication compliance: a meta-analysis. Am J Med. 2007;120(8):713-719.

16. Krum H. Critical assessment of calcium antagonists. Aust Fam Physician. 1997;26(7):841-845, 847-848.

17. Zhang X, Hintze TH. Amlodipine releases nitric oxide from canine coronary microvessels: an unexpected mechanism of action of a calcium channel-blocking agent. Circulation. 1998;97(6):576-580.

18. Jukema JW, van der Hoorn JW. Amlodipine and atorvastatin in atherosclerosis: a review of the potential of combination therapy. Expert Opin Pharmacother. 2004;5(2):459-468.

19. Mason RP, Marche P, Hintze TH. Novel vascular biology of thirdgeneration L-type calcium channel antagonists: ancillary actions of amlodipine. Arterioscler Thromb Vasc Biol. 2003;23(12):2155-2163.

20. Chung M, Calcagni A, Glue P, Bramson C. Bioavailability of amlodipine besylate/atorvastatin calcium combination tablet. J Clin Pharmacol. 2006;46(9):1030-1037.

21. Battleman D, Peterson E. Estimated prevalence of comorbid hypertension and dyslipidemia and therapeutic goal attainment among US adults in 2000, utilizing data from the National Health and Nutrition Examination Survey (NHANES III). J Manag Care Pharm. 2004;10:186.

22. Blank R, LaSalle J, Reeves R, Maroni J, Tarasenko L, Sun F. Single-pill therapy in the treatment of concomitant hypertension and dyslipidemia (the amlodipine/atorvastatin gemini study). J Clin Hypertens (Greenwich). 2005;7(5):264-273.

23. Chung M, Calcagni A, Glue P, Bramson C. Effect of food on the bioavailability of amlodipine besylate/atorvastatin calcium combination tablet. J Clin Pharmacol. 2006;46(10):1212-1216.

24. Preston RA, Harvey P, Herfert O, et al. Reduction in Framingham cardiovascular risk with concomitant treatment of hypertension/dyslipidemia with amlodipine/atorvastatin. Am J Hypertens. 2005;18:A226.

25. Messerli FH, Bakris GL, Ferrera D, et al. Efficacy and safety of coadministered amlodipine and atorvastatin in patients with hypertension and dyslipidemia: results of the AVALON trial. J Clin Hypertens (Greenwich). 2006;8(8):571-581; quiz 582-583.

26. Preston RA, Sun F, Tarasenko L. Safety and tolerability of coadministered amlodipine and atorvastatin in patients with concomitant hypertension and dyslipidemia in the Respond study. Am J Hypertens. 2005;18:A92-A93.

27. Mason RP. A rationale for combined therapy with a calcium channel blocker and a statin: evaluation of basic and clinical evidence. Curr Drug Targets Cardiovasc Haematol Disord. 2005;5(6):489-501.

28. Cohn J, Neutel J, Houston M, et al. Early improvements in vascular compliance following coadministration of amlodipine and atorvastatin in patients with concomitant hypertension and dyslipidemia. The Avalon Arterial Wall Compliance (AWC) trial. San Francisco, CA: Program and abstracts from the 20th Annual Scientific Meeting of the American Society of Hypertension, May 14-18; 2005.
29. Leibovitz E, Beniashvili M, Zimlichman R, Freiman A, Shargorodsky M, Gavish D. Treatment with amlodipine and atorvastatin have additive effect in improvement of arterial compliance in hypertensive hyperlipidemic patients. Am J Hypertens. 2003;16(9 Pt 1):715-718.

30. Fogari R, Preti P, Zoppi A, et al. Effects of amlodipine-atorvastatin combination on inflammation markers and insulin sensitivity in normocholesterolemic obese hypertensive patients. Eur J Clin Pharmacol. 2006;62(10):817-822.

31. Fogari R, Derosa G, Lazzari P, et al. Effect of amlodipine-atorvastatin combination on fibrinolysis in hypertensive hypercholesterolemic patients with insulin resistance. Am J Hypertens. 2004;17(9):823-827.

32. Delsing DJ, Jukema JW, van de Wiel MA, et al. Differential effects of amlodipine and atorvastatin treatment and their combination on atherosclerosis in ApoE * 3-Leiden transgenic mice. $J$ Cardiovasc Pharmacol. 2003;42(1):63-70.

33. Mason RP, Walter MF, Day CA, Jacob RF. Intermolecular differences of 3-hydroxy-3-methylglutaryl coenzyme a reductase inhibitors contribute to distinct pharmacologic and pleiotropic actions. Am J Cardiol. 2005;96(5A):11F-23F.

34. Jukema JW, Zwinderman AH, van Boven AJ, et al. Evidence for a synergistic effect of calcium channel blockers with lipid-lowering therapy in retarding progression of coronary atherosclerosis in symptomatic patients with normal to moderately raised cholesterol levels. The REGRESS Study Group. Arterioscler Thromb Vasc Biol. 1996;16(3):425-430.

35. Lewis EJ, Hunsicker LG, Clarke WR, et al. Renoprotective effect of the angiotensin-receptor antagonist irbesartan in patients with nephropathy due to type 2 diabetes. $N$ Engl J Med. 2001;345(12):851-860.

36. Major outcomes in high-risk hypertensive patients randomized to angiotensin-converting enzyme inhibitor or calcium channel blocker vs diuretic: The Antihypertensive and Lipid-Lowering Treatment to Prevent Heart Attack Trial (ALLHAT). JAMA. 2002;288(23):2981-2997.

37. Julius S, Weber MA, Kjeldsen SE, et al. The Valsartan Antihypertensive Long-Term Use Evaluation (VALUE) trial: outcomes in patients receiving monotherapy. Hypertension. 2006;48(3):385-391.

38. Dahlof B, Sever PS, Poulter NR, et al. Prevention of cardiovascular events with an antihypertensive regimen of amlodipine adding perindopril as required versus atenolol adding bendroflumethiazide as required, in the Anglo-Scandinavian Cardiac Outcomes Trial-Blood Pressure Lowering Arm (ASCOT-BPLA): a multicentre randomised controlled trial. Lancet. 2005;366(9489):895-906.

39. Poulter NR, Wedel H, Dahlof B, et al. Role of blood pressure and other variables in the differential cardiovascular event rates noted in the Anglo-Scandinavian Cardiac Outcomes Trial-Blood Pressure Lowering Arm (ASCOT-BPLA). Lancet. 2005;366(9489):907-913.

40. Williams B, O'Rourke M. The Conduit Artery Functional Endpoint (CAFE) study in ASCOT. J Hum Hypertens. 2001;15(Suppl 1):S69-S73.

41. Packer M, O'Connor CM, Ghali JK, et al. Effect of amlodipine on morbidity and mortality in severe chronic heart failure. Prospective Randomized Amlodipine Survival Evaluation Study Group. $N$ Engl J Med. 1996;335(15):1107-1114

42. Pitt B, Byington RP, Furberg CD, et al. Effect of amlodipine on the progression of atherosclerosis and the occurrence of clinical events. PREVENT Investigators. Circulation. 2000;102(13):1503-1510.

43. Nissen SE, Tuzcu EM, Libby P, et al. Effect of antihypertensive agents on cardiovascular events in patients with coronary disease and normal blood pressure: the CAMELOT study: a randomized controlled trial. JAMA. 2004;292(18):2217-2225.

44. Cannon $\mathrm{CP}$, Braunwald $\mathrm{E}, \mathrm{McCabe} \mathrm{CH}$, et al. Intensive versus moderate lipid lowering with statins after acute coronary syndromes. $N$ Engl $J$ Med. 2004;350(15):1495-1504.

45. LaRosa JC, Grundy SM, Waters DD, et al. Intensive lipid lowering with atorvastatin in patients with stable coronary disease. $N$ Engl $J$ Med. 2005;352(14):1425-1435.

46. Shepherd J, Barter P, Carmena R, et al. Effect of lowering LDL cholesterol substantially below currently recommended levels in patients with coronary heart disease and diabetes: the Treating to New Targets (TNT) study. Diabetes Care. 2006;29(6):1220-1226. 
47. Pedersen TR, Faergeman O, Kastelein JJ, et al. High-dose atorvastatin vs usual-dose simvastatin for secondary prevention after myocardial infarction: the IDEAL study: a randomized controlled trial. JAMA. 2005; 294(19):2437-2445.

48. Nissen SE, Tuzcu EM, Schoenhagen P, et al. Effect of intensive compared with moderate lipid-lowering therapy on progression of coronary atherosclerosis: a randomized controlled trial. JAMA. 2004;291(9):1071-1080.

49. Koren MJ, Hunninghake DB. Clinical outcomes in managed-care patients with coronary heart disease treated aggressively in lipid-lowering disease management clinics: the alliance study. J Am Coll Cardiol. 2004;44(9):1772-1779.

50. Athyros VG, Mikhailidis DP, Papageorgiou AA, et al. Relationship between LDL-C and non-HDL-C levels and clinical outcome in the GREek Atorvastatin and Coronary-heart-disease Evaluation (GREACE) Study. Curr Med Res Opin. 2004;20(9):1385-1392.

51. Erdine S, Ro YM, Tse HF, et al; Gemini-AALA Investigators. Singlepill amlodipine/atorvastatin helps patients of diverse ethnicity attain recommended goals for blood pressure and lipids (the Gemini-AALA study). J Hum Hypertens. 2009;23(3):196-210.

52. Hobbs FD, Gensini G, Mancini GB, et al. Can combining different risk interventions into a single formulation contribute to improved cardiovascular disease risk reduction? Rationale and design for an international, open-label program to assess the effectiveness of a single pill (amlodipine/atorvastatin) to attain recommended target levels for blood pressure and lipids (The JEWEL Program). Int J Cardiol. 2006;110(2):242-250.

53. Flack JM, Victor R, Watson K, et al. Improved attainment of blood pressure and cholesterol goals using single-pill amlodipine/atorvastatin in African Americans: the CAPABLE trial. Mayo Clin Proc. 2008;83(1):35-45.

54. Preston RA, Harvey $\mathrm{P}$, Herfert $\mathrm{O}$, et al. A randomized, placebo-controlled trial to evaluate the efficacy, safety, and pharmacodynamic interaction of coadministered amlodipine and atorvastatin in 1660 patients with concomitant hypertension and dyslipidemia: the respond trial. J Clin Pharmacol. 2007;47(12):1555-1569.

55. Sever P, Dahlof B, Poulter N, et al. Potential synergy between lipid-lowering and blood-pressure-lowering in the Anglo-Scandinavian Cardiac Outcomes Trial. Eur Heart J. 2006;27(24):2982-2988.
56. Lindgren $\mathrm{P}$, Buxton $\mathrm{M}, \mathrm{Kahan} \mathrm{T}$, et al. Amlodipine+atorvastatin is cost effective compared to atenolol + atorvastatin, amlodipine or atorvastatin alone: the Anglo-Scandinavian Cardiac Outcomes Trial (ASCOT). Eur Heart J. 2007;28(Abstr Suppl):857.

57. Smith TW CS, Tang SSK, et al. Clinical and economic consequences of single pill combination of amlodipine/atorvastatin compared with a two-pill regimen in hypertension patients with additional cardiovascular risk factors. Eur Heart J. 2007;28(Abstr Suppl):857.

58. Tatti P, Pahor M, Byington RP, et al. Outcome results of the Fosinopril Versus Amlodipine Cardiovascular Events Randomized Trial (FACET) in patients with hypertension and NIDDM. Diabetes Care. 1998;21(4):597-603.

59. Dezii CM. A retrospective study of persistence with single-pill combination therapy vs. concurrent two-pill therapy in patients with hypertension. Manag Care. 2000;9(9Suppl):2-6.

60. Eron JJ, Yetzer ES, Ruane PJ, et al. Efficacy, safety, and adherence with a twice-daily combination lamivudine/zidovudine tablet formulation, plus a protease inhibitor, in HIV infection. AIDS. 2000;14:671-681.

61. Geiter LJ, O’Brien RJ, Combs DL, Snider Jr DE. United States Public Health Service Tuberculosis Therapy Trial 21: preliminary results of an evaluation of a combination tablet of isoniazid, rifampin and pyrazinamide. Tubercle. 1987;68(2 Suppl):41-46.

62. Melikian C, White TJ, Vanderplas A, et al. Adherence to oral antidiabetic therapy in a managed care organization: a comparison of monotherapy, combination therapy, and fixed-dose combination therapy. Clin Ther. 2002;24:460-467.

63. NDC dataset (personal communication from Novartis - November 2005).

64. Su WJ, Perng RP. Fixed-dose combination chemotherapy (Rifater/ Rifinah) for active pulmonary tuberculosis in Taiwan: a two-year follow-up. Int J Tuberc Lung Dis. 2002;6:1029-1032.

65. Taylor AA, Shoheiber O. Adherence to antihypertensive therapy with fixed-dose amlodipine besylate/benazepril $\mathrm{HCl}$ versus comparable component-based therapy. Congest Heart Fail. 2003;9:324-332.

66. Patel BV, Leslie RS, Foody JM, et al. Adherence with single pill amlodipine/atorvastatin vs a two pill regimen. Vasc Health Risk Manage. 2008;4(3):673-681.
Vascular Health and Risk Management

\section{Publish your work in this journal}

Vascular Health and Risk Management is an international, peerreviewed journal of therapeutics and risk management, focusing on concise rapid reporting of clinical studies on the processes involved in the maintenance of vascular health; the monitoring, prevention and treatment of vascular disease and its sequelae; and the involvement of

\section{Dovepress}

metabolic disorders, particularly diabetes. This journal is indexed on PubMed Central and MedLine. The manuscript management system is completely online and includes a very quick and fair peer-review system, which is all easy to use. Visit http://www.dovepress.com/ testimonials.php to read real quotes from published authors. 